\title{
La (In) Justicia Ambiental: Claves Desde la Escala y la Configuración Escalar
}

Claudia Bucio Feregrino ${ }^{1}$

\section{RESUMEN}

En México, el estatus hegemónico del extractivismo está siendo interpelado por personas, pueblos o comunidades afectadas, al evidenciar y denunciar los impactos consustanciales al avance y desarrollo de proyectos de megaminería. La conflictividad socioambiental que emerge por el extractivismo, expresa el complejo entramado en el que convergen y divergen actores sociales, corporaciones trasnacionales e instituciones del estado que, en bloques o coaliciones y mediante la intervención de las distintas escalas geográficas, ponen de manifiesto rupturas o quiebres que definen y explican la trayectoria de la conflictividad. Con base en un estudio de caso, este trabajo plantea un episodio contrahegemónico en la política de desarrollo extractivista del estado, con el objetivo de discutir. dos categorías clave para la Ecología Política y la justicia ambiental: la escala y la configuración escalar. El conflicto bajo estudio emergió, a finales de 2012, en torno al proyecto de megaminería a cielo abierto "Cerro del Jumil", también conocido como proyecto Esperanza, para la extracción de oro y plata en el centro-occidente de Morelos.

Palabras clave: Conflictividad Socioambiental; Extractivismo; Escala; Configuración Escalar.

\footnotetext{
${ }^{1}$ Maestra en Estudios Regionales (Instituto de Investigaciones Dr. José María Luis Mora). Doctoranda del Posgrado en Geografía de la Universidad Nacional Autónoma de México. ORCID: https://orcid.org/0000-0001-8849-1219; e-mail: claudia.b.feregrino@gmail.com
} 
$\mathrm{E}$ n América Latina los proyectos extractivos no son un asunto novedoso. La ampliación de la frontera extractiva, entendida como la expansión territorial de un modelo alentado por el avance tecnológico y sostenido en la modificación o en el aprovechamiento de vacíos en los aparatos legales e institucionales, ha significado la reconfiguración de los territorios; debido a que su "vocación" no estaba asociada a prácticas extractivas, o bien, porque otras actividades productivas, además de la megaminería y de la extracción de hidrocarburos, adquirieron rasgos que habían sido propios de éstos. ${ }^{2}$

Para explicar procesos de países como Bolivia y Ecuador, bajo los gobiernos de Evo Morales y Rafael Correa respectivamente, fue preciso introducir el término neoextractivismo para enfatizar el destacado papel del aparato estatal en la redistribución de los ingresos asociados a los proyectos extractivos mediante la implementación de programas sociales.3 Sin embargo, los proyectos políticoeconómicos de estos gobiernos dieron continuidad y profundizaron la fórmula "a mayor extractivismo, menor democracia", entendida como la única vía posible para reducir los índices de pobreza y marginación social derivados de la alta concentración de la riqueza social. ${ }^{4}$

En México, la hegemonía del modelo de desarrollo extractivista se gestó, a partir de la década del noventa, con la reconfiguración de los arreglos jurídicoinstitucionales que impulsaron la inversión extranjera directa, dieron seguridad a la inversión privada y facilitaron que la tierra, bajo el régimen de propiedad social, entrara a la lógica del mercado. ${ }^{5}$ En el caso de la minería, se mantuvo el carácter de

\footnotetext{
2 Maristella Svampa, Del cambio de época al fin de ciclo. Gobiernos progresistas, extractivismo y movimientos sociales en América Latina, ( Buenos Aires: Edhasa, 2017).

${ }^{3}$ Eduardo Gudynas, El nuevo extractivismo progresista del Sur. Tesis sobre un viejo problema bajo nuevas expresiones, en Acosta, et. al, Colonialismos del siglo XXI. Negocios extractivos y defensa del territorio en América Latina, (Barcelona: Icaria Editorial, 2011), p. 75-92; Eduardo Gudynas, Extracciones, extractivismo y extrahecciones. Un marco conceptual sobre la apropiación de los recursos naturales, Observatorio del Desarrollo, 8, (: Centro Latinoamericano de Ecología Social, 2013) https://www.researchgate.net/publication/281748932_Extracciones_Extractivismo_y_Extrahecciones_Un_marco_conceptual_sobre_la_apropiacion _de_recursos_naturales; Edgardo Lander, Tensiones/contradicciones en torno al extractivismo en los procesos de cambio: Bolivia, Ecuador y Venezuela, en E. Lander, C. Arze, J. Gómez, P. Ospina y V. Álvarez, Promesas en su laberinto. Cambios y continuidades en los gobiernos progresistas en América Latina, (La Paz: Instituto de Estudios Peruanos/Centro de Estudios para el Desarrollo Laboral y Agrario/Centro Internacional Miranda, 2013), p. 1-35.

${ }^{4}$ A diferencia de los casos señalados, en México, el llamado "giro a la izquierda" que representó 2018 cuando Andrés Manuel López Obrador asumió la presidencia, se dio en un momento en el que el "consenso de los commodities" empezó a ser incierto. Hasta antes de 2018, la hegemonía de este modelo estuvo sustentada en un aparato estatal que sirvió para garantizar la proliferación de los proyectos extractivos, sin una redistribución y sin un cuestionamiento hacia las políticas neoliberales. Maristella Svampa, Ibidem.

5 Juan José Carrillo, Neoliberalismo, reestructuración jurídica y extractivismo en México, en R. Gutiérrez y M. Burgos (coord.). Globalización, neoliberalismo y derechos de los pueblos indígenas en México, (México: UNAM/Instituto de Investigaciones Jurídicas, 2020), p. 159-208 http://ru.juridicas.unam.mx:80/xmlui/handle/123456789/58503
} 
preferente sobre cualquier otro tipo de actividad -a excepción de la explotación de yacimientos petroleros-, lo que sirvió para estimular el desarrollo de proyectos de exploración y extracción de recursos minerales implementados por grandes corporaciones transnacionales. Estos cambios obedecieron al aumento en los precios de los minerales, especialmente el oro y la plata, y a la demanda de éstos y otros bienes de la naturaleza que, a nivel global, sirvieron para mantener la expansión y reproducción del sistema capitalista.

Bajo un "nuevo" modelo, denominado como social y ambientalmente responsable, los proyectos extractivos siguen operando mediante el cercamiento de los territorios y con un esquema operativo que, por el método y las técnicas que utilizan, suponen un alto consumo de agua y energía. En esta dirección, el papel de las instituciones del estado ha sido el de garantizar las condiciones sociales, políticas y económicas necesarias para el avance y el cierre de este tipo de proyectos. Sin embargo, esta hegemonía está siendo disputada por las luchas y movimientos sociales que resisten y se oponen al poder de las corporaciones para dislocar el despliegue de la minería de gran escala o megaminería.

Múltiples e importantes debates desde distintos campos disciplinares y, en algunos casos, vinculados a procesos y movimientos de defensa de la tierra, el territorio y los bienes comunes naturales, han cuestionado "lo viejo" y "lo nuevo" del extractivismo en aras de establecer los aspectos estructurales de un fenómeno que responde a un largo proceso de despojo.6 De ahí que buena parte de los estudios sobre la conflictividad socioambiental, particularmente los que se ocupan y se producen desde América Latina, se han enfocado en: 1) la persistencia del modelo extractivista ante los cambios en los proyectos políticos y las corrientes ideológicas que en la región, bajo el rótulo progresista y de izquierda, condenaron al modelo neoliberal; 2) la conflictividad socioambiental inherente a este modelo.

\footnotetext{
${ }^{6}$ Francisco López Bárcenas propone cuatro ciclos del despojo con el objetivo de mostrar que, pese a las particularidades de cada uno, desde la época colonial la minería en México ha estado orientada por los intereses de los capitales privados y extranjeros. Para las comunidades rurales, campesinas 0 indígenas, esto ha significado la reconversión, violenta o no, de sus tierras y otros bienes comunes naturales, que habían sido destinados a la producción agrícola, a enclaves mineros. López Bárcenas, F. La vida o el mineral. Los cuatro ciclos del despojo minero en México, (Ciudad de México: Akal, 2017).
} 
La multiplicación y profundización de la conflictividad socioambiental derivada de la imposición de la megaminería, práctica extractiva paradigmática, es innegable. Estos conflictos refieren a las tensiones y disputas que se gestan en torno a las consecuencias irreversibles que suponen el uso y el aprovechamiento de los bienes naturales comunes, cuando son interpelados por pueblos, comunidades o grupos sociales afectados.7

Esta interpelación tiene tres posibles vertientes: a) los emprendimientos mineros son antagónicos a las formas y modos vigentes o tradicionales de relación entre una sociedad y los bienes naturales; b) los grupos o comunidades afectadas negocian para modificar las condiciones de implementación de los emprendimientos mineros, lo que incluye la retribución justa por el arrendamiento de tierras, el cumplimiento de acuerdos, etc.; c) la aceptación de un proyecto resulta de la coerción ejercida por la corporación y ésta es, al menos, enunciada por las personas afectadas, lo que supone que aún en la aceptación existen tensiones subyacentes, o éstas se presentan como formas consensuadas de coerción. Las relaciones de antagonismo, negociación y aceptación implicadas en estas vertientes no son excluyentes, antes bien, se combinan en distintos grados y momentos.

Con esta definición de conflictividad socioambiental se ponen de relieve las dinámicas y los vínculos que se tejen entre tres grandes bloques de actores, o coaliciones, que convergen y divergen en torno a un modo específico de apropiación de la naturaleza: un bloque que promueve el proyecto, generalmente compuesto por lazos de acotada duración y con objetivos de tipo legal y burocrático, entre las corporaciones transnacionales y el aparato estatal, en sus distintos niveles; un bloque, o coalición opositora, integrado por población local afectada, así como grupos, instituciones y organizaciones, regionales o nacionales, que apoyan los procesos de lucha y defensa de quienes están directamente implicados y afectados por los emprendimientos mineros; un tercer bloque, mucho más difuso y permeable,

\footnotetext{
${ }^{7}$ Ma. Fernanda Paz, Conflictos socioambientales en México: ¿qué está en disputa?, en M.F, Paz y N. Risdell (coord.), Conflictos, conflictividades y movilizaciones socioambientales en México: problemas comunes, lecturas diversas, Ciudad de México: UNAM-CRIMA/MA Porrúa, 2014); Ma. Fernanda Paz, Luchas en defensa del territorio. Reflexiones desde los conflictos socioambientales en México, Acta sociológica, 73, (Ciudad de México: UNAM, 2017), p.197-219. DOI: http://dx.doi.org/10.22201/fcpys.24484938e.2017.73; Gabriela Merlinsky (comp.), Cartografías del conflicto ambiental en Argentina, (Buenos Aires: Ciccus/CLACSO, 2013). http://biblioteca.clacso.edu.ar/clacso/se/20140228033437/Cartografias.pdf
} 
integrado por la combinación de los dos anteriores y cuya característica y tendencia es la negociación o mediación.

La conformación de coaliciones o bloques entre actores sociales divergentes, así como sus posturas, intereses o demandas no son anteriores, sino que resultan y se explican por el devenir de la conflictividad socioambiental. ${ }^{8}$ Aun cuando las coaliciones y los posicionamientos de aceptación, rechazo y negociación que representan tienden a condensarse, éstos se van modificando debido al carácter itinerante del conflicto. Frente a esta cualidad emergente y de sedimentación de algunos de sus componentes, se propone caracterizar y explicar la conflictividad a partir de dos factores: la escala y la configuración espacial, y los momentos o fases que definen la trayectoria del conflicto. Mediante un estudio de caso, y con base en esta propuesta, son planteadas las fisuras o quiebres que significaron un episodio contrahegemónico en la política de desarrollo extractivista del estado.

\section{LA ESCALA Y LA CONFIGURACIÓN ESCALAR}

La justicia ambiental tiene, desde sus orígenes, una fuerte carga geográfica. Es un concepto que surgió con las movilizaciones de Estados Unidos durante la década de 1980 en rechazo a las afectaciones derivadas de la disposición de desechos industriales. En ese contexto, la justicia ambiental estuvo anclada a una particular forma de injusticia, el racismo, implicado en la localización de los sitios donde eran dispuestos dichos materiales, esto es, en los barrios donde la población era mayoritariamente pobre, latina o afrodescendiente. A partir de ese momento, tanto en Estados Unidos como en Europa, tuvo lugar una diversificación de las preocupaciones y problemas ambientales, lo que amplió las categorías y los enfoques de la justicia ambiental. $^{9}$

De acuerdo con Julie Sze, la Ecología Política (EP) y la geografía crítica radical generalmente coinciden en que la escala no es sólo un término técnico medido

\footnotetext{
${ }^{8}$ Gabriela Merlinsky, et. al, Defender lo común. Qué podemos aprender de los conflictos ambientales, 1ra edición, (Buenos Aires: Instituto de Investigaciones Gino Germani/Facultad de Ciencias Sociales-UBA/Grupo de Estudios Ambientales/Área de Estudios Urbanos, 2018) http://geaiigg.sociales.uba.ar/libro-cuadernillo-gea/

${ }^{9}$ Esme G. Murdock, "A history of environmental justice. Foudations, narratives, and perspectives, en Coolsaet, B. (ed.), Environmental Justice. Key issues, (Nueva York: Routledge, 2021), p. 6-17: Giovanna Di Chiro, "Environmental justice", en J. Adamson, William A. Gleason, David N. Pellow (ed.), Keywords for environmental studies, (New York: New University York Press, 2016), loc. 2725 de 6909, Kindle.
} 
objetivamente, también es socialmente construido, históricamente contingente y políticamente disputado. La escala, plantea Sze, se ha vuelto un asunto preponderante debido a que los problemas ambientales frecuentemente son entendidos como asuntos que "cruzan" o "saltan" de escala, y con ello se produce un "desajuste espacial" entre, por ejemplo, la contaminación ambiental y su regulación política: "mientras los problemas ambientales complejos sean multiescalares en el espacio y el tiempo, la escala seguirá siendo una herramienta conceptual clave en los estudios ambientales interdisciplinarios". ${ }^{10}$

Otros autores, como Nikolas C. Heynen y Erik Swyngedouw, señalaron que a diferencia de la EP, buena parte de los estudios sobre justicia y equidad ambiental tienden a ser "estrechamente centrados" y, al tratar sobre lugares geográficos específicos, limitan su generalidad y, si bien han dado cierta centralidad a las relaciones de poder, fallan al no dar cuenta de cómo son parte integral de un sistema político económico capitalista -preocupación central para un área de investigación que, en años recientes, ha sido impulsada por ambos autores, la ecología política urbana marxista.11 Esta crítica refuerza la importancia que tiene la escala en su articulación con uno de los aspectos que, para David N. Pellow, es clave para una justicia ambiental crítica - perspectiva que aborda las limitaciones y tensione dentro de la justicia ambiental a partir de cuatro grandes cuestiones que deben ser problematizadas: 1) la multiplicidad de formas de desigualdad y sus intersecciones; 2) enfoque multiescalar; 3) el poder estatal, esto es, el grado en que varias formas de poder y desigualdad social son vistas como arraigadas e integradas en la sociedad; y 4) la prescindibilidad (expandability) de las poblaciones humanas y no-humanas que se enfrentan "a los estados, las industrias y otras fuerzas económicas y políticas".12 Sobre el segundo aspecto, Julie Sze et al., señalan:

Las luchas por la escala no son simplemente sobre quién controla una unidad territorial determinada, sino sobre la escala en la que se define esa unidad [...] La escala no se entiende como natural, sino como producida socialmente

\footnotetext{
10 Julie Sze, "Scale" en Adamson, J., William A. Gleason, David N. Pellow (eds.), Keywords for environmental studies, (New York: New York University Press, 2016),, loc. 4743 of 6909, Kindle.

11 Nikolas C. Heynen y Erik Swyngedouw, "Urban political ecology, justice and the politics of scale", Antipode, 35:5, (2003), p. 909-910. https://doi.org/10.1111/j.1467-8330.2003.00364.x

12 David N. Pellow, "Critical environmental justice studies", en Brendan Coolsaet (ed.), Environmental Justice. Key issues, (Nueva York: Routledge, 2021), p. 293-302. https://doi.org/10.4324/9780429029585
} 
(derivada de los procesos sociales, y a menudo de la lucha social) y socialmente productora (ejerciendo coerción y hegemonía en un sentido gramsciano). ${ }^{13}$

Erik Swyngedouw abona, tanto a la problematización de la escala como herramienta analítica, y a su vez, avanza en la tercera cuestión que apunta Pellow, el poder estatal. Swyngedouw, desde un enfoque que coloca en el centro la noción de metabolismo social, plantea que la vida social está, necesariamente, "localizada" y "situada". Esto es, los seres humanos, al producir el sustento social y material de la vida metabolizan la naturaleza socialmente producida, lo que "se constituye en y a través de relaciones sociales espaciales/temporales que operan en una cierta extensión escalar". ${ }^{14}$

Un análisis que parte de una escala geográfica dada supone una importante dificultad: aprehender el mundo de manera dinámica. En este sentido, Swyngedouw afirma que "las configuraciones escalares son el resultado de procesos socioespaciales que regulan y organizan las relaciones de poder social. Como construcción geográfica, las escalas se convierten en espacios alrededor de los cuales se realizan y ejecutan coreografías del poder social". De ahí que la organización y reorganización de la escala constituya un elemento integrante de la estrategia y de las luchas por el control. ${ }^{15}$ Con relación al estado, Swyngedouw señala que éste ha sido entendido como la escala en la que se dirimen y condensan las contradicciones y tensiones sociales, no como objeto, sino como espacio y escala geográfica sobresalientes.

El estado-nación ha sido señalado como el lugar preeminente para la cristalización y resolución de estas tensiones y conflictos. Esta ha sido, y sigue siendo, una escala importante para la regulación y negociación de la vida social, económica y cultural, y para la mencionada articulación de los procesos de des y re-territorialización [...] La producción del espacio a través de la perpetua reelaboración de las redes de flujo de circulación y acumulación capitalista descarta configuraciones escalares y escalas de gobernanza preexistentes, al tiempo que otras nuevas son producidas. ${ }^{16}$

En el conflicto socioambiental que aquí se analiza, lo local es predominante por dos razones: 1) es el espacio y la escala en donde colisionan la extracción de

\footnotetext{
13 Julie Sze, et. al., "Defining and contesting Environmental Justice: socio-natures and the politics of scale in the Delta", en Ryan Holifield, Michael Porter y Gordon Walker, Spaces of Environmental Justice, (Oxford: Antipode/ Wiley-BlackWell, 2010). https://doi.org/10.1002/97814444322767.ch8

${ }^{14}$ Erik Swyngedouw, "Scaled geographies: nature, place, and the politics of scale", en E. Sheppard y R. B. McMaster (ed.), Scale and geographic inquiry: nature, society and method, (: Blackwell Publishing Ltd, 2004), p. 131. https://onlinelibrary.wiley.com/doi/book/10.1002/9780470999141

15 Swyngedouw, "Scaled geographies", p. 131-133.

${ }^{16}$ Erik Swyngedouw, "Globalisation or 'glocalisation'? Networks, territories and rescaling", Cambridge Review of International Affairs, 17:1, p. 32. https://doi.org/10.1080/0955757042000203632
} 
recursos minerales, localizados bajo la superficie territorial; y 2) la oposición a esa extracción deviene en la defensa de un espacio territorializado; dicho de otro modo, a esta escala y por el conflicto, se relacionan actores que, de otro modo, no lo estarían.

Si bien lo local es una escala espacial prioritaria, esto no significa que los actores sociales renuncien o no intenten acceder a otras escalas; por el contrario, el éxito o fracaso, tanto de la implementación de un proyecto extractivo como de la resistencia u oposición hacia éste dependerá del acceso, la influencia o la dominación que efectivamente ejerzan en otras escalas mediante las alianzas políticas y los vínculos sociales, formales o informales densos o laxos, que establezcan aun si éstos resultan temporal y espacialmente acotados. No ceñirse a lo local resulta estratégicamente fundamental en la medida en que, práctica y discursivamente, los actores coligados por el conflicto incorporan, para afirmar o rechazar, lo que se instituye desde las escalas global y nacional.

\section{El PROYeCto CERRo Jumil EN El CENTRO-OCCIDENTE DE MORELOS}

En 1994 la empresa Recursos Cruz del Sur (RCS), filial de YK3, obtuvo la concesión minera para explorar un yacimiento minero que había descubierto en las inmediaciones de los cerros El Jumil y Colotepec, ubicados en el municipio de Temixco, Morelos. Entre 1996 y 1997, otra empresa canadiense, Teck Cominco Ltd a través de su filial Minera Teck, adquirió la concesión y realizó trabajos de exploración. Sin embargo, a finales de 1998, Recursos Cruz del Sur recuperó la concesión y, en el 2002, renovó la concesión ante la Secretaría de Economía. Al año siguiente, obtuvo otra concesión, pero ahora con una duración de cincuenta años -con la reforma a la ley minera de 1992, la vigencia fue ampliada y, además, incluyó tanto la exploración como la explotación. ${ }^{17}$

Esperanza Silver de México (ESM), filial de la canadiense Esperanza Resources Corp., compró las concesiones mineras La Esperanza y Esperanza II a Recursos Cruz del Sur. ${ }^{18}$ Esperanza Silver estaba interesada en la explotación de plata y continuó con

\footnotetext{
17 Esperanza Silver Corporation. NI-43-101 Technical Report Cerro Jumil Project, Mexico, (Canadá: William D. Bond y Dean Turner/Esperanza Resources Corp, 2008). https://www.sec.gov/

18 Las negociaciones entre Esperanza Silver de México y Recursos Cruz del Sur iniciaron en mayo de 2003 con la celebración de un acuerdo formal. En octubre de 2006, Recursos Cruz del Sur recibió de Esperanza Silver el pago de C\$417,375 dólares en efectivo más 500 mil en acciones
} 
los trabajos de perforación. En 2005, ESM informó el descubrimiento de una importante reserva de oro, lo que estimuló a la corporación a adquirir más concesiones. $^{19}$

Tabla 1. Concesiones mineras en el centro-occidente de Morelos

\begin{tabular}{|c|c|c|c|c|c|}
\hline $\begin{array}{c}\text { Nombre del } \\
\text { lote }\end{array}$ & $\begin{array}{l}\text { Superficie } \\
\text { (ha) }\end{array}$ & $\begin{array}{l}\text { No. de } \\
\text { Título }\end{array}$ & Inscripción & $\begin{array}{c}\text { Concesionario } \\
\text { actual }\end{array}$ & Duración \\
\hline La Esperanza & 437 & 215624 & $05 / 03 / 2002$ & \multirow{2}{*}{$\begin{array}{ll}\text { Original } & \text { RCS) } \\
\text { Esperanza } & \text { Silver } \\
\text { de México } & \end{array}$} & \multirow[t]{7}{*}{50 años } \\
\hline Esperanza II & 1,270 & 220742 & $30 / 09 / 2003$ & & \\
\hline Esperanza III & 1,359 & 228265 & $20 / 10 / 2006$ & \multirow{5}{*}{$\begin{array}{l}\text { Esperanza Silver } \\
\text { de México }\end{array}$} & \\
\hline Esperanza IV & 1,338 & 231734 & $15 / 04 / 2008$ & & \\
\hline Esperanza V & 278 & 234011 & $15 / 05 / 2009$ & & \\
\hline Esperanza VI & 9,704 & 234755 & $11 / 08 / 2009$ & & \\
\hline Esperanza VII & 639 & 234784 & $14 / 08 / 2009$ & & \\
\hline & \multicolumn{3}{|c|}{ Superficie total $15025 \mathrm{ha}$} & & \\
\hline
\end{tabular}

Fuente: Elaboración propia con base en datos de la Secretaría de Economía, 2017 y de Esperanza Resources Corporation, 2011.20

Por su ubicación, las siete concesiones mineras comprenden parte de los municipios de Temixco, Miacatlán, Xochitepec y, en menor medida, Cuernavaca (mapa 1). El territorio concesionado ha sido clasificado por la corporación en tres tipos de área:

1. El área-recurso conocida como Cerro Jumil ("Cerro Jumil Resource") que comprende los recursos medidos, indicados e inferidos, ubicados en la Zona Oeste (WZ), Zona Sureste (SEZ) y Las Calabazas (LCZ). Esta área corresponde a los cerros de El Jumil y Colotepec ubicados en el lote La Esperanza.

2. Cuatro áreas objetivo adyacentes conocidas como Northern Contact, NE Intrusive Contact, SW Extension y Colotepec, las cuales también están localizadas en el lote La Esperanza.

para finalizar la compra-venta de las concesiones; Esperanza Resources Corporation. NI-43-101 Updated Technical Report Preliminary Economic Assessment. Cerro Jumil Project, Morelos, México, Colorado: Golder Associates Inc./Esperanza Resources Corp., 2011. http://www.alamosgold.com/home/default.aspx

${ }^{19}$ En 2007 fueron concesionadas otras 484ha a un particular, José C. Sandoval, denominadas La Conquista (C-CIV). Información que la Dirección General de Desarrollo Minero (DGDM) promueve con el objetivo de ofertar los proyectos de los concesionarios mineros y vincularlos con inversionistas nacionales e internacionales -la DGDM es una dependencia de la Coordinación General de Minería. Por su localización, estas concesiones representan un potencial interés para ESM.; Secretaría de Economía. Portafolio de proyectos mineros de la DGDM, 2015 https://www.gob.mx/se/acciones-y-programas/mineria-portafolio-de-proyectos-de-la-dgdm

${ }_{20}$ Secretaría de Economía. Cartografía de concesiones mineras del Servicio Geológico Mexicano, 2017. https://www.sgm.gob.mx/GeolnfoMexGobMx/; Esperanza Resources Corporation. "NI-43-101". 
3. Seis áreas objetivo distantes a los recursos conocidos que, en orden de importancia, son Coatetelco, Alpuyeca, Pluma Negra, Mercury Mines, La Víbora y Jasperoid de Toros. Este conjunto está localizado en el resto de las concesiones.

Mapa 1. Concesiones mineras y áreas de interés

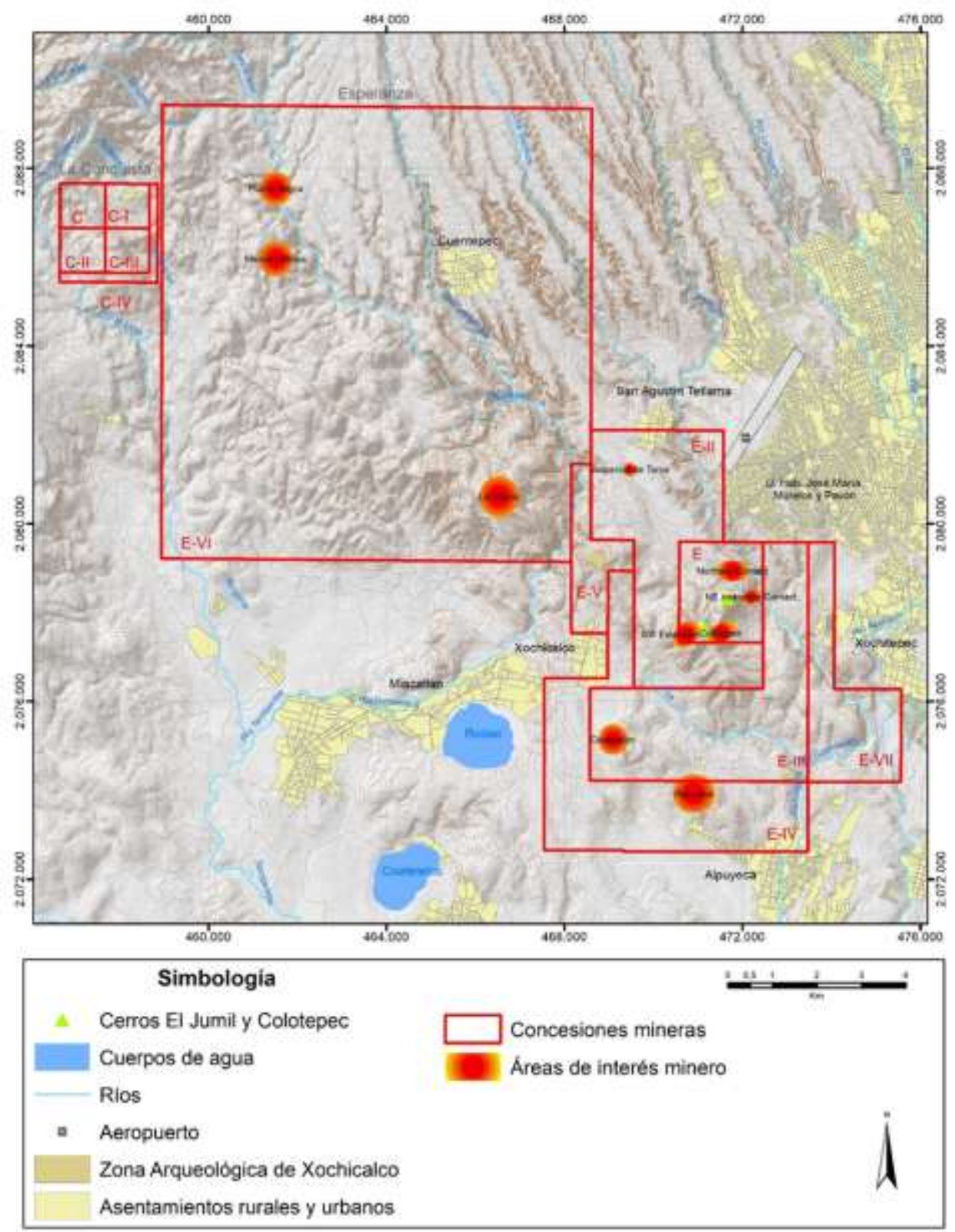

Fuente: Elaboración propia con base en Esperanza Resources Corporation, 2011.21

En el reporte técnico National Instrument 49-103 (NI-49-103) de 2011, Esperanza Resources Corp. manifestó que en el área-recurso Cerro Jumil, los recursos medidos e indicados suman 935, 0000 onzas de oro equivalente, mientras que los 
inferidos son de 252, 000 onzas de oro equivalente, con una ley mínima de corte de 0.3 gramos por tonelada. La corporación también reportó un recurso inferido de plata que suma un total $3,322,000$ onzas de plata con un promedio de 43.2 gramos por tonelada, con una ley de 25 gramos de plata por tonelada. Este recurso está fuera del área-recurso dominante, en una zona adyacente a las áreas mineralizadas de Las Calabazas y Zona Oeste. ${ }^{22}$

En noviembre de 2012, la corporación sometió la Manifestación de Impacto Ambiental (MIA) del Proyecto Cerro Jumil ante las autoridades ambientales para iniciar la fase de explotación. El proyecto consistía en la extracción de oro y plata bajo el método conocido como de tajo o "a cielo abierto", conformado por dos tajos, un patio de lixiviación, áreas de depósito de material con bajo o nulo mineral y "zonas de conservación". Este modelo abarcaría un área de 696.92 hectáreas (ha), las cuales se encuentran, principalmente, en el área de la concesión La Esperanza.

En la MIA, la corporación planteó que la producción diaria de mineral, durante los 11.6 años de vida útil de la mina, sería de 18,000 toneladas (esto es 6, 570,000 t/año). La inversión requerida para la ejecución del proyecto, incluidas las etapas de preparación del sitio, construcción, operación y cierre, fue calculada en \$126’574, 460 dólares (mapa 2). La empresa proyectó, además, la construcción de uno o dos pozos para la extracción de agua "al interior o en las inmediaciones" del proyecto, y consideró el aprovechamiento del cauce del río Los Sabinos, ubicado al norte del polígono, mediante la construcción de una "obra de toma". El consumo de agua anual estimado es de $760,000 \mathrm{~m}^{3}{ }^{32}$

\section{Mapa 2. Proyecto Cerro Jumil de Esperanza Silver de México}

\footnotetext{
22 Esperanza Resources Corporation, "NI-43-101",.

23 Para la construcción del patio de lixiviación, la corporación consideró cinco fases de ampliación, dependiendo del avance de las operaciones. La capacidad total del patio contemplada sería de 54 millones de toneladas. El tajo 1 (T1) abarcaría un área de 98.99ha con 50m de profundidad, mientras que el tajo 2 (T2) sería de 497ha con una profundidad de 90m en promedio; Secretaría de Medio Ambiente y Recursos Naturales. Oficio No. SGPA/DGIRA/DG 03865, junio 5, 2013; Esperanza Silver de México S.A. de C.V. Manifestación de Impacto Ambiental Modalidad Particular, Mina Esperanza, Tetlama, Morelos, (: Esperanza Silver de México/Planeación y Proyectos de Ingeniería S.C./Ordóñez Profesional S.C., 2013), [Folio 17MO2012M0005], p. II-30.
} 


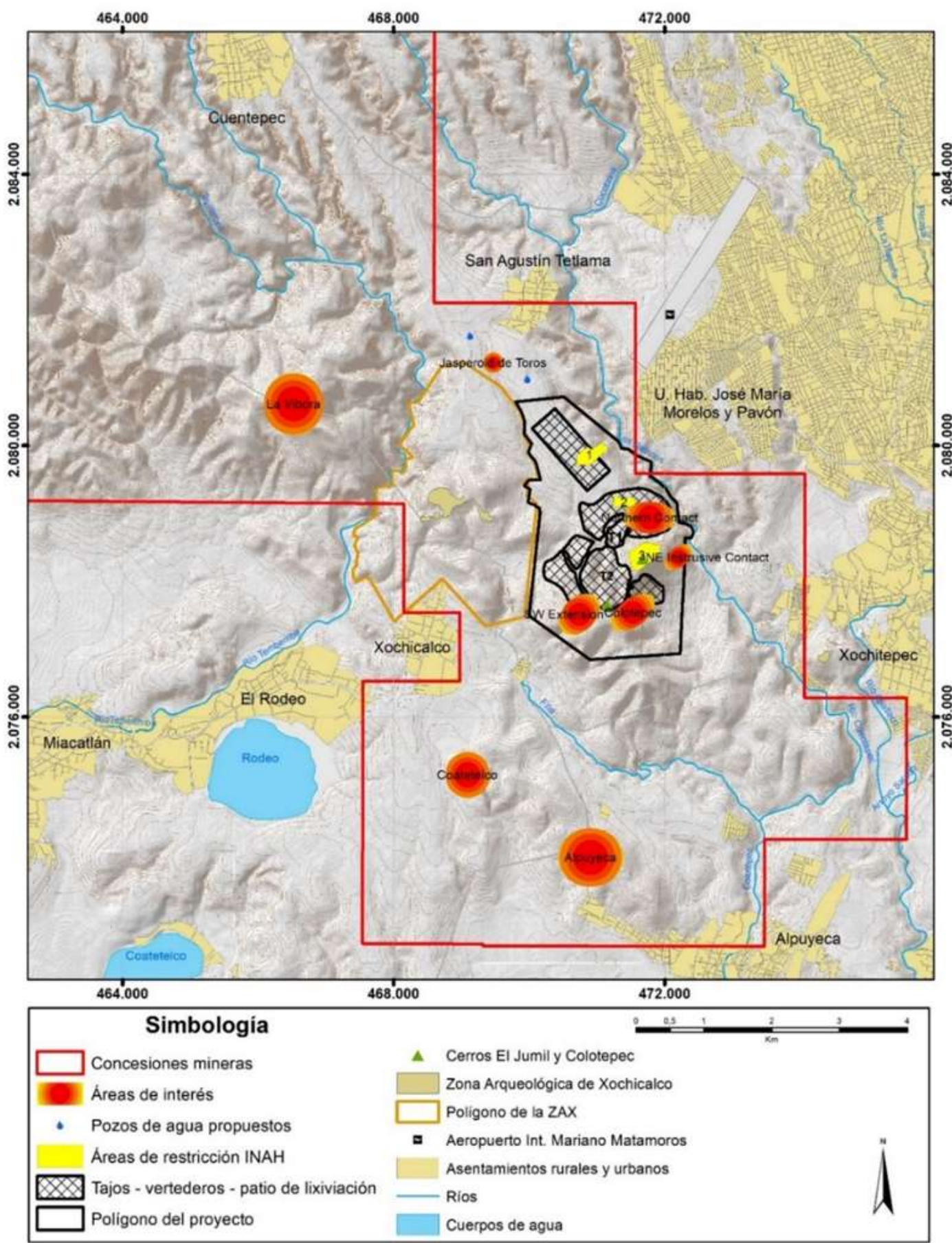

Fuente: Elaboración propia con base en Esperanza Silver de México, 2013 y DOF, 1994. ${ }^{24}$

Al interior del área del proyecto, la empresa definió cuatro usos de suelo: 1) uso agrícola y 2) uso pecuario, ambos en propiedad particular y de uso común; 3) áreas sin uso aparente con vegetación de Selva baja Caducifolia y secundaria; y 4) tres polígonos de restricción temporal establecidos por el Instituto Nacional de

\footnotetext{
${ }^{24}$ Esperanza Silver de México S.A de C.V., "Manifestación de Impacto Ambiental"; Diario Oficial de la Federación. "Decreto por el que se declara zona de monumentos arqueológicos el área conocida como Xochicalco, ubicada en los municipios de Temixco y Miacatlán, Mor.", 18 de febrero de 1994.
} 
Antropología e Historia (INAH), los cuales son no contiguos y comprenden un área total de 33.96ha: el polígono núm.1 es de 13.30ha; el núm.2 de 6.00ha y el núm.3 de 14.70ha. ${ }^{25}$ Estos polígonos de restricción son resultado de los convenios de colaboración suscritos entre la corporación y el Instituto Nacional de Antropología e Historia (INAH) en 2010 y 2011, para la liberación de la zona y hacer factibles las actividades de exploración y explotación.

\section{TRAYECTORIA Y (RE)CONFIGURACIÓN ESCALAR DEL CONFLICTO}

El periodo analizado inicia en el año 2003 y se prolonga hasta 2019. Este recorte temporal ubica a la corporación y sus intereses de exploración y extracción minera como un momento que, aun siendo anterior a las fases de efervescencia y de conformación del rechazo social y de la coalición opositora, es clave para entender el devenir de la conflictividad. La reconstrucción del conflicto supone una aproximación a la secuencia temporal de los hechos; sin embargo, lo que aquí interesa es poner de relieve dos procesos imbricados: la suspensión temporal del Cerro Jumil Project y la expropiación de tierras por causa de utilidad pública. El episodio y los eventos que constituyen la trama del conflicto, se sintetizan y explican a continuación (tabla 2). ${ }^{26}$

De 2003 a 2012, la corporación cimentó gradualmente el consenso social, enfocándose en la comunidad indígena de San Agustín Tetlama, del municipio de Temixco, para asegurar su acceso a la superficie territorial donde se localiza la reserva aurífera descubierta en los cerros de El Jumil y Colotepec. Con esta comunidad, la corporación celebró varios contratos de ocupación temporal para las actividades de exploración; en el último, suscrito en octubre de 2011, también fueron autorizadas la construcción del complejo minero y el inicio de los trabajos de explotación. Además, con las comunidades de Tlajotla y Coatetelco, del municipio de Miacatlán, Esperanza Silver celebró contratos de ocupación temporal, en marzo y mayo de 2012,

\footnotetext{
${ }^{25}$ Esperanza Silver de México S.A de C.V., "Manifestación de Impacto Ambiental"., p. II-14

${ }^{26}$ La reconstrucción de un caso de conflictividad "bajo estudio" consiste en identificar y delimitar el episodio y los eventos que determinaron su devenir; ejercicio que, a su vez, sirve para diferenciar y establecer las fases o periodos del conflicto a partir de dos cualidades básicas: lo latente y lo manifiesto. Esta reconstrucción se sustenta en el método narrativo planteado por Abbott. Andrew Abbott, Time matters. On theory and method, (Texas: The University of Chicago Press, 2001). Esta herramienta metodológica ha sido retomada por: Ma. Fernanda Paz, "Deterioro y resistencias. Conflictos socioambientales en México", en Darcy Tetreault, Heliodoro Ochoa y Eduardo Hernández (coords.), Conflictos socioambientales y alternativas de la sociedad civil, Guadalajara: ITESO, 2012) p. 27-47; Merlinsky, et al., "Defender lo común"; y Michael Barzelay y Juan Carlos Cortázar, "Una guía práctica para la elaboración de estudios de caso sobre buenas prácticas en gerencia social", (Washington D.C.: INDES/BID, 2004). https://publications.iadb.org/es/publicacion/15330/una-guia-practica-para-la-elaboracion-de-estudios-decaso-sobre-buenas-practicas
} 
respectivamente -cabe destacar que las tierras sobre las que Tlajota tiene derecho, se encuentra en la concesión Esperanza VI, a 13km del área mineralizada de principal interés, circunscrita a la concesión La Esperanza.

Durante ese periodo, la comunidad de Tetlama, particularmente, las autoridades agrarias, se colocaron como el actor con mayor afinidad al proyecto $\mathrm{y}$, por ende, al que la corporación le otorgó el más alto nivel de importancia en su ejercicio del poder. En el siguiente rango fueron considerados el INAH, así como el ayudante municipal, las escuelas y el centro de salud de Tetlama, debido a que en su relación con estos actores no hubo, hasta ese momento, algún tipo de disenso. ${ }^{27}$

En agosto de 2012, inició el proceso de expropiación e indemnización entre el INAH y las comunidades de Tetlama y Miacatlán que resultó de la declaratoria federal de "Zona de monumentos arqueológicos del área conocida como Xochicalco" (ZAX), emitida en 1994. Con este decreto, se determinó que un área de la propiedad social de las dos comunidades sería destinada a actividades de carácter y utilidad pública: la preservación e investigación de la zona arqueológica. Si bien 2013 fue el año de mayor efervescencia, este proceso se articularía con el del conflicto debido a que el área objeto de expropiación, localizada dentro de la poligonal delimitada por la declaratoria, es colindante al proyecto minero (mapa 2).

En junio de 2013, la Secretaría de Medio Ambiente y Recursos Naturales (Semarnat) negó la autorización ambiental solicitada por la corporación para iniciar la fase de explotación. Esto no sólo constituyó una decisión institucional que se limitó al señalamiento de inconsistencias técnicas. Antes bien, derivó de la presión social ejercida por la coalición opositora, conformada a finales de 2012, que cuestionó el desarrollo del proyecto y, en cierta medida, las concesiones mineras. Frente a este escenario, la adquisición del proyecto y de los títulos de concesión por una

\footnotetext{
${ }^{27}$ Esta jerarquización y mapeo de los actores sociales fue incluida en la MIA presentada en 2013. Si bien se trata de un documento elaborado por consultores ambientales externos a petición de la corporación, la valoración de los actores se basó en acuerdos, vínculos o relaciones con cada uno de ellos; Esperanza Silver de México S.A. de C.V. "Manifestación de Impacto Ambiental". Además de los contratos para la ocupación de las tierras y de los convenios celebrados con el INAH, Esperanza Silver implementó las siguientes acciones: en 2009, se comprometió a financiar estudios para conocer las casusas del alto índice de habitantes diagnosticados con cáncer, de la comunidad de Alpuyeca; en Tetlama, entre 2009 y 2013, Esperanza Silver arregló la fachada de la iglesia e hizo algunas donaciones, útiles escolares y computadoras; además, en agosto de 2013, representantes de la corporación participaron de la "fiesta grande", práctica ritual de celebración que la comunidad dedica, cada año, a San Agustín; Jesica Arellano, "Investiga CRIM causas de cáncer en Alpuyeca", El Sol de Cuernavaca, 17 de abril 17 de 2009. http://www.oem.com.mx/esto/notas/n1127166.htm; Florencio Hernández, "Cambian oro por centavos", Diario de Morelos, 24 de marzo de 2013 http://www.diariodemorelos.com/article/cambian-oro-por-centavos; Florencio Hernández, "Se aferran comuneros a estar bien", Diario de Morelos, 24 de marzo de 2013. http://www.diariodemorelos.com/article/se-aferran-comuneros-'estar-bien'-y-los-'espejitos'
} 
corporación más robusta, Alamos Gold, significó una salida y continuidad del conflicto que reconfiguró los alcances e implicaciones derivados de la disgregación entre Esperanza Silver de México y las instituciones del estado que, a nivel estatal y federal, gestionan y administran el patrimonio y los bienes naturales.

La coalición opositora emergió de la convergencia del movimiento opositor y las comunidades afectadas con dos instituciones del estado: el gobierno estatal, representado por Graco Ramírez, y la Secretaría de Desarrollo Sustentable (SDS). ${ }^{28}$ A este primer frente se sumaron el rechazo de investigadores del Centro INAH-Morelos, la rectificación del INAH a nivel federal, y los cuestionamientos del grupo político parlamentario del PRD -grupo que simpatizó, en 2013, con la propuesta de reforma a la Ley Minera impulsada por movimientos y organizaciones sociales a nivel nacional. ${ }^{29}$

El rechazo del gobierno estatal encabezado por Graco Ramírez no desafió plenamente la política federal de franca apertura hacia el desarrollo de megaproyectos, ni constituyó una sólida ruptura entre los distintos niveles de gobierno, pero puso en contradicción la política extractivista y las prácticas burocráticas que, en esa dirección, son desplegadas desde el estado. En octubre de 2012, durante una de las primeras declaraciones de rechazo al proyecto, Graco Ramírez, señaló:

Yo le dije al presidente que más que la plata y el oro que podría sacar esta empresa canadiense, era más importante lo que valía Xochicalco para nosotros. Y quiero decirles entonces que ese sitio arqueológico que es Xochicalco, que mucha gente no iba por la pestilencia que había [por el basurero] de Tetlama, una vez que se hizo la remediación ahora tendremos una mina, decidida irresponsablemente, y no vamos a permitirlo, vamos a preservar el medio ambiente y a cuidar ahora que abramos la carretera de Siglo XXI que va a

\footnotetext{
${ }^{28}$ Como parte de la evaluación de impacto ambiental, la corporación hizo público un extracto de la MIA en dos diarios de circulación local en noviembre de 2012. Unos días después, el 10 de diciembre de 2012, una mujer habitante del municipio de Temixco, solicitó que el proyecto fuera sometido a un proceso de consulta y reunión pública. Entre marzo y junio de 2013, el Movimiento Morelense contra las Concesiones Mineras de Metales Preciosos (MMCMMP), actor social que surgió y aglutinó el rechazo social hacia el proyecto minero, encabezó diversas acciones colectivas. ${ }^{28}$ Con el apoyo del Centro Mexicano de Derecho Ambiental (CEMDA), demandaron penalmente a la corporación por negar los inminentes daños ambientales; Lya Gutiérrez, "Alistan demanda penal contra minera Esperanza", Diario de Morelos, 20 de marzo de 2013. https://www.diariodemorelos.com/article/alistan-demanda-penal-contra-minera-esperanza. Organizaciones de nivel nacional o regionales, como el Frente Amplio Opositor a la Minera San Xavier y la Red Mexicana de Afectados Ambientales (Rema), entre otras, también coadyuvaron a la conformación de la oposición social.

${ }^{29}$ La posición oficial del INAH se explica por el recambio administrativo y la rectificación en la aceptación que, tácitamente, había otorgado a la empresa en materia de investigación arqueológica. Contrario a esta apertura y disposición hacia el proyecto que sostuvo antes de 2013, el Instituto se recolocó, no para ejercer y posicionarse como un actor que abiertamente se opone al avance y desarrollo de las actividades mineras, sino únicamente para cumplir con sus atribuciones y funciones sustanciales: protección y salvaguarda del patrimonio arqueológico. Sobre la propuesta de reforma a la Ley Minera: Jorge Peláez, "Legislación minera y derechos humanos: el derecho en la encrucijada", El cotidiano. Revista de la Realidad Mexicana Actual,194, (Ciudad de México: UAM-Azcapotzalco), p. 107-120. https://www.redalyc.org/articulo.oa?id=32542592011
} 
conectar a Miacatlán hasta el estado de México, abramos oportunidad de inversión para la zona surponiente. ${ }^{30}$

La ZAX y el valor turístico al que se apela, embonaron con la política de desarrollo del turismo, infraestructura e inversión que Graco respaldó y promovió desde el inicio de su gestión. Además, al solicitar el apoyo de las Secretarías del Trabajo y de Desarrollo Económico y de Turismo para impedir el avance del proyecto, el gobierno de Graco hizo de la minería a cielo abierto y del turismo dos iniciativas contrapuestas. Aun con este antecedente, el gobierno estatal fue cuestionado por respaldar otros megaproyectos, como el Proyecto Integral Morelos (PIM), y promover la construcción de una planta de valorización de residuos sólidos, ubicada entre Alpuyeca y el centro de Xochitepec. ${ }^{31}$

Otra pieza clave de esta coalición estuvo representada por autoridades de escala municipal. Por un lado, los ayudantes municipales de Coatetelco, Alpuyeca y de algunas colonias de Temixco, manifestaron su respaldo al movimiento opositor. Por el otro, los cabildos de los ayuntamientos de Xochitepec y Miacatlán, dos de los municipios afectados, se declararon "territorios libres de minería a tajo abierto por metales" y se comprometieron a no dar ninguna autorización que sirviera al avance del proyecto. ${ }^{32}$

Además de las declaratorias de territorio libre de minería, la modificación de dos instrumentos de competencia estatal, el Programa de Ordenamiento Ecológico y Territorial (POEREM) y la modificación al artículo 71 de la Ley de Desarrollo Rural Sustentable (LDRS), constituyeron una relativa disyunción entre la corporación y el

\footnotetext{
30 Gobierno de Morelos. Versión estenográfica del gobernador Graco Ramírez durante la inauguración de la Feria del Empleo de Turismo, 16 de octubre de 2012. https://morelos.gob.mx/

${ }^{31}$ El Plan Integral Morelos (PIM) consiste en la construcción de dos termoeléctricas, un gasoducto e infraestructura complementaria a cargo de las empresas españolas Elecnor, Enagas y Abegnoa, en los que además de Morelos, implica a los estados de Tlaxcala y Puebla. Samantha César, "Megaproyecto energético Proyecto Integral Morelos, México", Environmental Atlas Justice. última actualización 6 de noviembre de 2020. https://ejatlas.org/conflict/lucha-del-frente-de-pueblos-en-defensa-de-la-tierra-y-el-agua-morelos-puebla-tlaxcala-contra-el-proyecto-integralmorelos. De acuerdo con el gobierno estatal, la planta de valorización fue una iniciativa que, como parte de la Estrategia de Gestión Integral de Residuos, tenía como objetivo cerrar los tiraderos de basura a cielo abierto; lo que a su vez serviría para recuperar material potencialmente reciclable. La comunidad de Alpuyeca se opuso debido a que estaría ubicada muy cerca de Palo Bolero, argumentado los potenciales daños asociados a las filtraciones en el subsuelo; otro grupo afectado fue el de las personas que vivían de esta actividad, quienes finalmente aceptaron emplearse en la planta. La planta fue construida desde mediados de 2015 e inaugurada el 14 de febrero de 2017. Gobierno de Morelos, "Lista planta de valorización en Xochitepec", 3 de junio de 2016. http://morelos.gob.mx/?q=prensa/nota/lista-planta-de-valorizacion-en-xochitepec; Jaime Luis Brito, "Pobladores toman palacio municipal y bloquean el basurero de Alpuyeca", Revista Proceso, 13 de junio de 2017. https://www.proceso.com.mx/nacional/estados/2017/6/13/pobladores-toman-el-palacio-municipal-bloquean-el-basurero-de-alpuyeca-186055.html 32 Florencio Hernández. "Se suman contra minera", Diario de Morelos, 8 de octubre de 2013 https://www.diariodemorelos.com/article/se-sumancontra-minera; Florencio Hernández, "Rechazan en Miacatlán labor minera", Diario de Morelos, 23 de marzo de 2014 http://www.diariodemorelos.com/article/rechazan-en-miacatlán-labor-minera; Ayuntamiento de Xochitepec. Acta de cabildo SOC/HAX/18-02-15, 18 de febrero de 2015; Ayuntamiento de Miacatlán. Acta de cabildo. SEC/HAM/06-03-15, 6 de marzo de 2015.
} 
gobierno de Morelos. ${ }^{33}$ Sin embargo, esto no derivó en la disolución de un aspecto crucial: el convenio de ocupación temporal de las tierras suscrito entre la corporación y las autoridades agrarias de Tetlama, pese a que fue evidenciada la intervención de la Procuraduría Agraria de Morelos (PA-Morelos). ${ }^{34}$

Ante esto, en septiembre de 2014, Esperanza Silver de México emprendió una demanda de amparo indirecto contra el Comité de Ordenamiento Ecológico Regional del Estado de Morelos (COEREM) -organismo encargado de formular, aprobar, expedir, ejecutar, evaluar o modificar el POEREM; argumentando que, al restringirse el uso del cianuro, fueron violentados sus derechos de "libertad de trabajo, de irretroactividad, de audiencia y defensa, legalidad y seguridad jurídica". ${ }^{35}$

El Consejo Consultivo para el Desarrollo Sustentable del Núcleo Morelos (CCDS) se constituyó en un espacio en el que convergió una parte de la colación opositora. Los CCDS, dependientes de la Semarnat, fueron creados en el marco de la Ley General de Equilibrio Ecológico y la Protección al Medio Ambiente, como espacios en los que concurren y participan instituciones y dependencias públicas, instituciones académicas, organizaciones sociales y empresariales. ${ }^{36}$ Esta iniciativa surgió en atención a tres acciones de gubernamentalidad transnacional: el Acuerdo de Cooperación Ambiental de América del Norte suscrito por México, Canadá y Estados Unidos de 1993 que intentó promover la participación de la sociedad en la formulación de políticas públicas en materia medioambiental; el Plan Nacional de

\footnotetext{
${ }^{33}$ El 21 de junio de 2013, el gobierno de Morelos y la Semarnat suscribieron un convenio de coordinación que resultó en la creación del POEREM; instrumento que buscó regular la minería a tajo o a cielo abierto mediante la restricción del uso de cianuro, sustancia toxica utilizada en ese tipo de extracción. Al mismo tiempo, estipuló cuatro aspectos necesarios para el desarrollo de una "minería sustentable": a) que no reduzca la cobertura vegetal de los ecosistemas primarios; b) que no impacte a los cuerpos de agua superficiales y subterráneos, así como a los ecosistemas acuáticos; c) no podrán desarrollarse actividades extractivas que pongan en riesgo la salud de las poblaciones asentadas en las zonas de influencia; y d) para proteger el patrimonio histórico cultural, será necesario actuar conforme a las normas oficiales y disposiciones aplicables. Gobierno de Morelos, "Decreto por el que se expide el Programa de Ordenamiento Ecológico Regional del Estado de Morelos", Periódico Oficial Tierra y Libertad, núm. 5220, 6a Época, 29 de septiembre de 2014.

34 La firma del convenio para el arrendamiento de tierras tuvo lugar en las instalaciones de la delegación de la PA en Morelos. Hecho que fue evidenciado, hasta junio de 2013, por el entonces delegado de la procuraduría cuando aclaró que la PA-Morelos se limitó a facilitar las instalaciones, por instrucción del coordinador general de Programas Interinstitucionales de la PA; aun cuando no estaba de acuerdo. Florencio Hernández, "Cambian oro por centavos", Diario de Morelos, 24 de marzo de 2013, http://www.diariodemorelos.com/article/cambian-oro-porcentavos.

${ }^{35}$ Estrella Pedroza, "Violentaron sus derechos, afirma minera", El regional del Sur, 11 de marzo de 2015.

${ }^{36}$ La estructura de los consejos de participación y consulta es territorial y está compuesta de la siguiente manera: el Consejo Consultivo Nacional para el Desarrollo Sustentable, integrado por seis Consejos Consultivos Regionales (región noroeste, noreste, occidente, centro, sur y sureste), más treinta y dos Consejos Consultivos Núcleo (uno por cada entidad). Los consejos tienen como objetivos: 1) analizar leyes y normas sobre el medio ambiente; 2) observar su implementación; y 3) opinar sobre los asuntos y cuestiones que trabaja y atienden la Semarnat. Los consejos han tenido el auspicio de Programa de las Naciones Unidas para el Desarrollo (PNUD).
} 
Desarrollo de la administración de 2007-2012; y el Programa Sectorial de Medio Ambiente y Recursos Naturales del mismo periodo. ${ }^{37}$

Tabla 2. Episodio y eventos del conflicto socioambiental

\begin{tabular}{|c|c|c|c|}
\hline \multicolumn{4}{|c|}{$\begin{array}{l}\text { Eventos contemporáneos } \\
2013\end{array}$} \\
\hline \multicolumn{2}{|c|}{$\begin{array}{l}\text { El gobierno de Morelos y la Secretaría de } \\
\text { Desarrollo Sustentable (SDS) manifiestan } \\
\text { oposición al proyecto. }\end{array}$} & \multicolumn{2}{|c|}{$\begin{array}{l}\text { El Movimiento Morelense contra las Concesiones } \\
\text { Mineras de Metales Preciosos realiza diversas } \\
\text { acciones colectivas de información en rechazo al } \\
\text { proyecto. }\end{array}$} \\
\hline & \multicolumn{2}{|c|}{ Episodio } & Eventos posteriores \\
\hline 2010 & & \\
\hline $\begin{array}{l}\text { Esperanza Silver de México y el } \\
\text { INAH suscriben el primer } \\
\text { convenio de colaboración para el } \\
\text { desarrollo de actividades de } \\
\text { prospección y salvamento } \\
\text { arqueológico. }\end{array}$ & \multicolumn{2}{|c|}{$\begin{array}{l}\text { Semarnat niega la autorización } \\
\text { de Impacto Ambiental del } \\
\text { proyecto minero, presentada por } \\
\text { Esperanza Silver de México } \\
\text { (ESM) para el inicio de la fase de } \\
\text { explotación. }\end{array}$} & $\begin{array}{c}\text { El gobierno de Morelo } \\
\text { la prohibición de la "n } \\
\text { cielo abierto" en el Pro } \\
\text { Ordenamiento Ecolc } \\
\text { Regional del Estado de } \\
\text { (POEREM). }\end{array}$ \\
\hline $\begin{array}{l}2011 \\
\text { La corporación y la comunidad } \\
\text { de Tetlama acuerdan la } \\
\text { ocupación temporal de la tierra } \\
\text { en las instalaciones de la } \\
\text { Procuraduría Agraria Delegación } \\
\text { Morelos. }\end{array}$ & \multicolumn{2}{|c|}{$\begin{array}{c}\text { A solicitud de la población } \\
\text { afectada, Semarnat convoca a la } \\
\text { Reunión Pública de Información } \\
\text { (RIP), a la que asisten } \\
\text { representantes de ESM, } \\
\text { habitantes de Tetlama que } \\
\text { apoyan el proyecto y opositores, } \\
\text { incluido el secretario de la SDS. }\end{array}$} & $\begin{array}{c}2015 \\
\text { Los ayuntamientos de } \\
\text { Xochitepec y de Miacatlán } \\
\text { emiten, respectivamente, actas } \\
\text { de cabildo con las que se } \\
\text { declaran "territorios libres de } \\
\text { minería a tajo abierto por } \\
\text { metales". }\end{array}$ \\
\hline $\begin{array}{l}2012 \\
\text { Autoridades agrarias de los } \\
\text { Bienes comunales de Tetlama y } \\
\text { Miacatlán inician el proceso de } \\
\text { indemnización y expropiación } \\
\text { de las tierras con autoridades } \\
\text { federales, derivado del decreto } \\
\text { "Zona de monumentos } \\
\text { arqueológicos" de } 1994 \text {. }\end{array}$ & \multicolumn{2}{|c|}{$\begin{array}{l}\text { ESM presenta ante la Semarnat } \\
\text { la Manifestación de Impacto } \\
\text { Ambiental del proyecto. Un } \\
\text { extracto del documento fue } \\
\text { publicado en la prensa local y en } \\
\text { la Gaceta Ecológica, tal como lo } \\
\text { que dicta el proceso de } \\
\text { evaluación. }\end{array}$} & $\begin{array}{c}2017 \\
\text { La Secretaría de Economía } \\
\text { modifica y reduce el área de las } \\
\text { concesiones mineras para } \\
\text { descartar la Zona Arqueológica } \\
\text { de Xochicalco. }\end{array}$ \\
\hline \multicolumn{4}{|c|}{$\begin{array}{c}\text { Eventos relacionados } \\
2013 \\
\end{array}$} \\
\hline \multicolumn{2}{|c|}{$\begin{array}{l}\text { Esperanza Silver de México apoya al candidato } \\
\text { postulado para ocupar el cargo de Ayudante } \\
\text { municipal de Tetlama, quien resulta ganador. }\end{array}$} & \multicolumn{2}{|c|}{$\begin{array}{l}\text { El Congreso del Estado de Morelos decreta la } \\
\text { adición al artículo } 71 \text { de la Ley de Desarrollo Rural } \\
\text { Sustentable para restringir el uso del cianuro. }\end{array}$} \\
\hline \multicolumn{2}{|c|}{$\begin{array}{l}\text { Alamos Gold, otra corporación canadiense, } \\
\text { adquiere el proyecto y las concesiones mineras. }\end{array}$} & \multicolumn{2}{|c|}{$\begin{array}{l}\text { La Secretaría de Gobernación investiga a } \\
\text { ejecutivos de la empresa por "activismo político" y } \\
\text { por amenazas a la población. }\end{array}$} \\
\hline
\end{tabular}

Fuente: Elaboración propia con base en Gabriela Merlinsky, 2013 y Michael Barzelay y Juan Carlos Cortázar, 2004.38

\footnotetext{
37 Secretaría de Gobernación. Decreto por el que se crean los Consejos Consultivos para el Desarrollo Sustentable de la Secretaría de Medio Ambiente y Recursos Naturales, Diario Oficial de la Federación, Tomo DCXCVI, núm. 20, 29 de septiembre de 2011 http://www.dof.gob.mx/ 38 Merlinsky, "Cartografías"; Barzelay y Cortazar, "Una guía práctica".
} 
Representantes del sector académico del CCDS Núcleo Morelos introdujeron la problemática en torno al proyecto minero, por primera vez, en su sesión del 21 de enero de 2013 y, con la anuencia de sus integrantes, se mantuvo hasta finales de 2014. Una primera acción del Consejo fue su intervención en la Reunión Pública de Información (RPI) convocada por la Semarnat con el fin de escuchar y emitir las recomendaciones y observaciones que estimaran convenientes sobre el proyecto. ${ }^{39}$ Además, algunos integrantes del CCDS organizaron una reunión en Xochicalco, días previos a la RPI. Durante la reunión, arqueólogos del INAH manifestaron su desacuerdo hacia el proyecto, pero habitantes de Tetlama, portando machetes y aparentemente en estado de ebriedad, interrumpieron y provocaron a los asistentes. ${ }^{40}$

En cambio, a esta misma escala, la segmentación del territorio en áreas de restricción y de autorización para el desarrollo de actividades mineras establecidas por el INAH, constituyó otro elemento de quiebre al demostrarse, con el proceso de expropiación e indemnización, que las concesiones se sobreponían a la Zona Arqueológica de Xochicalco y su poligonal de protección, colindantes con el área del proyecto. Esto explica por qué, en diciembre de 2017, el área concesionada fue modificada con el objetivo de descartar la ZAX y su museo de sitio (mapa 3). ${ }^{41}$

Las tensiones vinculadas a la expropiación de tierras se mantuvieron y profundizaron la distancia entre dos de los actores de la coalición opositora: el INAH y los comuneros de Miacatlán que, a diferencia de Tetlama, cuestionaron el proceso debido a la poca trasparencia con que actuaron las autoridades agrarias $\mathrm{y}$, específicamente, por representar una "venta de los cerros". Aunque el Instituto modificó su posición frente al proyecto minero, los intereses entre éstos y sus

\footnotetext{
${ }^{39}$ Secretaría de Medio Ambiente y Recursos Naturales. Gaceta Ecológica, Año XI, Separata N DGIRA/007/2013, 14 de febrero de 2013.

${ }^{40} \mathrm{~A}$ las sesiones del Consejo, además de sus integrantes habituales, participaron habitantes de Miacatlán y representantes del Consejo de Pueblos de Morelos. En conjunto, plantearon diversas estrategias para la defensa del territorio: a) iniciar el proceso para declarar la zona afectada como una "zona de protección cultural y de biodiversidad", Área Natural Protegida (ANP) o Unidad de Manejo para la Conservación de la Vida Silvestre (UMA); b) solicitar a la Defensoría de Oficio que emprenda las acciones necesarias para suspender el proyecto minero; c) concientizar, brindar información y diseñar alternativas productivas para la comunidad de Tetlama; d) capacitar a grupos de personas para que difundan información en el resto de las comunidades afectadas: El Rodeo, Alpuyeca, Coatetelco, Tetlama y Milpillas; e) enviar cartas al Congreso de la Unión, a la Embajada de Canadá y a la DGIRA -las cuales se elaboraron y enviaron entre marzo y abril de 2013; f) demandar la anulación de las concesiones mineras mediante una carta dirigida a la Secretaría de Desarrollo Económico (SEDECO) y a Secretaría de Economía del Estado.

${ }^{41}$ En marzo de 2015 el abogado, asesor y vocero de las autoridades agrarias de Tetlama y Miacatlán negó que el convenio de ocupación suscrito con la corporación se hubiera hecho sobre el área objeto de expropiación y que, por en esa medida, se comprometiera la ZAX y su poligonal; poco después, el área de asuntos jurídicos del INAH declaró que el proceso fue suspendido al descubrir que, en dicho convenio, sí se incluyó la ZAX; Diario de Morelos, "Venden Xochicalco a minera", Diario de Morelos, 24 de marzo de 2015. En 2016, Alamos Gold emitió un comunicado señalando que había iniciado "los trámites correspondientes para cancelar sus concesiones dentro de esa zona -refiriéndose a la ZAX-, lo que permitiría concluir el proceso de expropiación"; Alamos Gold, "A la opinión pública morelense", 1 de marzo de 2016.
} 
estrategias confluyeron, pero no se unificaron ni homogeneizaron; para el pueblo de Miacatlán, la expropiación de su patrimonio en beneficio de un bien público y el arrendamiento de tierras para la explotación minera tienen el mismo alcance, es una afectación de lo que les sustenta y orienta: la producción campesina y la apropiación comunitaria del territorio y de los bienes comunes.

\section{Mapa 3. Modificaciones a las concesiones mineras}

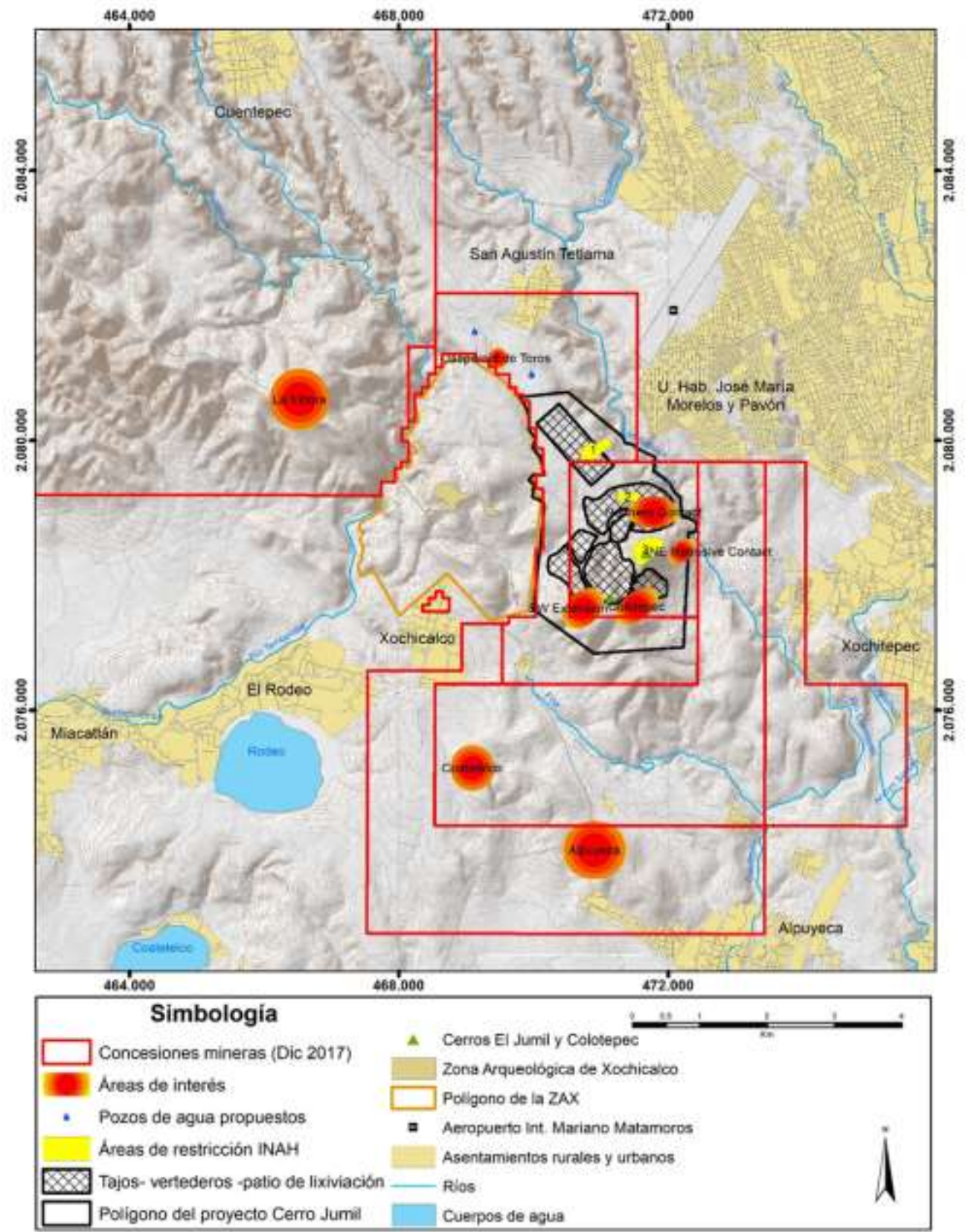

Fuente: Fuente: elaboración propia con base en Esperanza Silver de México, 2013; DOF, 1994 y Secretaría de Economía, 2017.42

42 Esperanza Silver de México S.A de C.V., "Manifestación de Impacto Ambiental"; Diario Oficial de la Federación. "Decreto"; Secretaría de Economía. Cartografía de concesiones mineras del Servicio Geológico Mexicano, 2017. https://www.sgm.gob.mx/GeolnfoMexGobMx/ 
La oposición al proyecto minero tuvo consecuencias específicas en la comunidad de Tetlama. Es decir, el horizonte de coerción trazado por la corporación se erigió en la posible suspensión de los derechos agrarios, utilizada como medida de sanción intracomunitaria hacia personas que se opusieran o que, de alguna manera, manifestaran su rechazo. ${ }^{43}$

hay muchos comuneros que no quieren revelarse porque tienen miedo a una sanción a sus derechos agrarios, y saben lo que va a pasar y por cobardía prefieren quedarse callados, otros más, por avaricia están a favor del proyecto, porque la empresa ha prometido varias obras y acciones a favor de la comunidad mismas que no ha cumplido como la instalación de energía eléctrica. ${ }^{44}$

Además de las autoridades agrarias de Tetlama, alineadas a los intereses de la corporación, el presidente municipal de Temixco, cargo que en ese momento estaba representado por Miguel Ángel Colín Nava, celebró el descubrimiento del área mineralizada. ${ }^{45}$ Sin embargo, pocos días antes de la resolución de la MIA, Graco Ramírez exhortó al cabildo de Temixco pidiéndole "un posicionamiento inequívoco de que no compartan este proyecto [...] la mina no se va a abrir y espero me acompañen en esa lucha a nombre de todos los morelenses". ${ }^{46}$ Colín Nava reviró y justificó su postura: "yo no estoy a favor de la minera, estoy a favor del empleo"; además, aseguró "que hay una línea perredista, la cual sigue y es a favor de la gente". ${ }^{47}$

La coalición opositora consiguió que la empresa postergara el inicio de la fase de explotación. Sin embargo, los vínculos que sostuvieron este conjunto de actores sociales divergentes, decrecieron después de la negación de la autorización en materia de impacto ambiental en 2013. Esto se explica por el tipo de vínculos que

\footnotetext{
43 En el expediente general agrario de los Bienes comunales de Tetlama, quedó asentada la suspensión temporal de los derechos de once comuneros, con fecha del 9 de julio de 2013, de acuerdo con el artículo 23 II fracción de la Ley Agraria, sin especificar los motivos; dado que algunos de ellos fueron relegados de los pagos correspondientes del proceso de indemnización, pese a que sus parcelas también fueron objeto de expropiación, por no alinearse a la iniciativa de la corporación, ambos aspectos estuvieron engarzados (notas manuscritas en posesión del autor, 8 de diciembre de 2017). Sobre el concepto de horizonte de coerción Claudio Garibay, "Clúster minero global: instauración de horizontes de coerción y resistencia en sociedades locales mexicanas", en Leticia Duran, Anja Nyjren, y Anne Cristina de Vega-Leitner, (eds.) Naturaleza y neoliberalismo en América Latina, (UNAM, 2019), p. 165-214. https://doi.org/10.22201/crim.9786073022231e.2019

${ }_{44}$ Raúl Morales, "Continúan las presiones de la minera a cielo abierto Esperanza Silver en Tetlama", La Jornada Morelos, 27 de septiembre de 2014. http://www.jornadamorelos.com/2014/9/27/politica_nota_14.php

45 7DíasTV. "Descubren mina de oro y plata en Tetlama", 2013 [video] https://www.youtube.com/watch?v=YrebxXLQJHo

46 Gobierno de Morelos. "Exhorta Graco Ramírez a cabildo de Temixco no aprobar la ejecución de la mina en Tetlama", 4 de junio de 2013 http://morelos.gob.mx/?q=exhorta-graco-ramírez-cabildo-de-temixco-no-aprobar-la-ejecución-de-la-mina-en-tetlama

47 Jessica Arellano, "Seguirá la línea que dicte el PRD en el tema", El Sol de Cuernavaca, 6 de marzo de 2013. http://www.oem.com.mx/elsoldecuernavaca/notas/n2903032.htm
} 
mantuvieron, relativamente densos y sustentados en la idea de comunidad, pero también de tipo instrumental limitados a cuestiones de corto plazo. ${ }^{48}$

Los vínculos formalizados entre la comunidad de Tetlama y la corporación mediante el arrendamiento de tierras y los beneficios sociales prometidos son de tipo instrumental debido al carácter contractual que les encuadra y acota. Del mismo modo, los vínculos no formales entre las comunidades afectadas y el movimiento opositor con las instituciones del estado, no carecen de rasgos instrumentales debido a que el sentido de la coalición opositora no trascendió una vez alcanzado el objetivo específico, la no autorización ambiental; sobre todo, por los valores que resultaron irreconciliables: la propiedad y apropiación social del territorio y los bienes comunes, frente a la expropiación por causa de utilidad pública y los bienes propiedad de la nación y de interés público.

A diferencia de las instituciones del estado, el primer frente de la coalición opositora, esto es, las comunidades afectadas, el movimiento social opositor y las redes de organizaciones que les apoyaron, aun con una diversidad de valores, construyeron lazos cuya densidad y robustez se sustentan en un discurso y prácticas comunes, la defensa del territorio -área densa de la coalición. Cualidades ausentes en los vínculos establecidos con el resto de la coalición opositora.

Observada en conjunto, la coalición opositora aglutinó actores sociales divergentes en torno a la no autorización de la MIA; síntesis discursiva que, a escala estatal, sirvió para frenar el avance del proyecto. Si bien esto condensó un discurso común amplio, no comprendió una compatibilidad de valores debido a que el "puenteo" (interacciones instrumentales) se sobrepuso a la extensión que reduciría la distancia ideológica y de valoración entre ellos (interacciones y lazos sociales densos) -esto alude a los dos tipos de procesos de encuadre, frame bridging y frame extension, los cuales no forzosamente están mutuamente implicados. ${ }^{49}$

\footnotetext{
48 Monica Di Gregorio, "Networking in environmental movement organisations coalitions: interest, values or discourse?", Environmental politics, 1:21 (2012): p. 1-25. https://doi.org/10.1080/09644016.2011.643366

49 Para Monica Di Gregorio los vínculos de una coalición son densos porque 1) descansan en la similitud de valores facilitando interacciones densas (homophily), o 2) porque una comunicación densa es lo que subyace y apoya coaliciones discursivas amplias. En el segundo, "la densidad de la interacción sustenta actividades de encuadre (framing) en curso y las prácticas discursivas redefinen y anticipan las reivindicaciones y posiblemente conducen a la convergencia de significados". Esto último explica la emergencia de redes de coaliciones amplias donde la redefinición del problema y la compatibilidad de valores son posibles aun con la diversidad de valores; Di Gregorio, "Networking”, (2012), p. 2-7.
} 


\section{CONCLUSIONES}

Entre 2003 y 2012, la corporación minera dominó la escala local del conflicto. Al afianzar su proyecto con la comunidad de San Agustín Tetlama, Esperanza Silver consiguió el acceso a un área inicial para el desarrollo del proyecto. En este periodo, Esperanza Silver resolvió ante una institución federal otro de los requerimientos para el desarrollo de su proyecto: la liberación de la zona y los vestigios arqueológicos. Si bien la actual legislación sobre el patrimonio arqueológico contempla la participación de empresas de carácter privado que, en este caso se dio mediante de la celebración de convenios, el interés de la minera entró en tensión y cuestionó una de las funciones básicas del INAH, la salvaguarda del patrimonio.

Esta configuración escalar del conflicto tuvo como punto de inflexión la negación de la MIA en junio 2013. A partir de este episodio, lo local dejó de referirse, únicamente, a la escala de las comunidades afectadas, desbordando el límite territorial definido por la propiedad social de la tierra, parcelada o común, contigua o no. La coalición opositora, al integrar y articular actores sociales divergentes que actúan en más de una escala, además del resultado específico, impedir el inicio de la fase de explotación, logró que de 2013 a 2015 el rechazo social se colocara en otra escala, representado en el Consejo Consultivo para el Desarrollo Sustentable de Morelos al que accedió la coalición opositora.

Por lo tanto, Esperanza Silver de México no se limitó al diseño de un modelo de operaciones para la extracción de minerales; además de "solventar" las afectaciones socioambientales inminentes o potenciales vinculadas a sus actividades, debió obtener el consentimiento o licencia social para acceder al territorio. De ahí que la estrategia de la corporación haya incluido la construcción de un andamiaje de relaciones y prácticas orientadas a la gestión corporativa del disenso social. El área concesionada es un territorio-recurso que la corporación produce desde la escala global, no sólo porque el diseño y la gestión son resueltos en un lugar y desde una representación del espacio, distintos y contrapuestos al "espacio-objeto de la extracción"; sobre todo, porque la dominación que ahí se ejerce está orientada hacia 
esa escala: la producción y circulación de "recursos naturales" dispuestos para la reproducción del sistema capitalista.

En suma, el estudio de la conflictividad, mediante la reconstrucción y delimitación espaciotemporal (el conjunto de eventos y el episodio central, así como en la configuración escala), sirvió para explicar tres cuestiones fundamentales. Primero, la delimitación y caracterización de fases o momentos que conforman la trayectoria del conflicto, supone reconocer cambios y continuidades entre ellos. En esta dirección fueron descritas las fases de latencia del conflicto, antes y después de junio de 2013, en donde tuvieron lugar el proceso de expropiación de indemnización de tierras entre el INAH y las autoridades agrarias de los bienes comunales de Tetlama y Miacatlán; así como la modificación, a finales de 2017, del área concesionada a la corporación.

Segundo, el conflicto no puede reducirse a una contienda en la que se enfrentan actores sociales disímiles, y cuya "solución" estriba en que los bienes disputados son, simplemente, negociados. Como se planteó, opera un horizonte de coerción aun cuando la negociación y la aceptación tienen lugar.

Tercero, la identificación de elementos que radican en los márgenes del conflicto, o que no forman parte de los momentos álgidos o de las fases de mayor efervescencia, tienen un valor explicativo. En esta dirección fueron señalados: a) el problema de salud pública en la comunidad de Alpuyeca; y b) la suscripción del convenio de ocupación temporal para el arrendamiento de tierras en las oficinas de una dependencia federal, la PA, suceso previo al escalamiento de las tensiones sociales.

La conflictividad socioambiental puede ser entendida, entonces, como un proceso en el que las prácticas sociales - rutinas socioespaciales, de acuerdo con Swyngedouw-, se reconfiguran en función del re-escalamiento que tiene lugar, y en el que son disputadas las líneas de poder existentes, a la vez que se integran otras nuevas. 


\section{REFERENCIAS}

Abbott, A. Time matters. On theory and method, (Texas: The University of Chicago Press, 2001).

Di Chiro, G. "Environmental justice", en J. Adamson, William A. Gleason, David N. Pellow (ed.), Keywords for environmental studies, (New York: New University York Press, 2016), loc. 2725 de 6909, Kindle.

Alamos Gold Inc. A la opinión pública morelense, 1 de marzo de 2016. http://www.alamosgold.com/home/default.aspx

Arellano, J. "Investiga CRIM causas de cáncer en Alpuyeca", El Sol de Cuernavaca, 17 de abril, de 2009. http://www.oem.com.mx/esto/notas/n1127166.htm

Arellano, J. "Seguirá la línea que dicte el PRD en el tema", El Sol de Cuernavaca, 6 de marzo de 2013. http://www.oem.com.mx/elsoldecuernavaca/notas/n2903032.htm Ayuntamiento de Xochitepec. Acta de cabildo SOC/HAX/18-02-15, 18 de febrero de 2015.

Ayuntamiento de Miacatlán. Acta de cabildo. SEC/HAM/06-03-15, 6 de marzo de 2015.

Barzelay, M. y Cortázar, J.C. Una guía práctica para la elaboración de estudios de caso sobre buenas prácticas en gerencia social, (Washington D.C: Instituto Interamericano para el Desarrollo Social/Banco Interamericano de Desarrollo, 2004). https://publications.iadb.org/es/publicacion/15330/una-guia-practica-para-laelaboracion-de-estudios-de-caso-sobre-buenas-practicas

Brito, J.L. "Pobladores toman palacio municipal y bloquean el basurero de Alpuyeca", $\begin{array}{lllllll}\text { Revista } & \text { Proceso, } & 13 & \text { de } & \text { junio }\end{array}$ https://www.proceso.com.mx/nacional/estados/2017/6/13/pobladores-toman-elpalacio-municipal-bloquean-el-basurero-de-alpuyeca-186055.html Carrillo, J.J. Neoliberalismo, reestructuración jurídica y extractivismo en México, en R. Gutiérrez y M. Burgos (coord.). Globalización, neoliberalismo y derechos de los pueblos indígenas en México, (Ciudad de México: UNAM/Instituto de Investigaciones Jurídicas, 2020),159-208.

http://ru.juridicas.unam.mx:80/xmlui/handle/123456789/58503 
César, S. "Megaproyecto energético Proyecto Integral Morelos, México, Altas de Justicia Ambiental, (2020). https://ejatlas.org/conflict/lucha-del-frente-de-pueblosen-defensa-de-la-tierra-y-el-agua-morelos-puebla-tlaxcala-contra-el-proyectointegral-morelo

Coolsaet, B. (ed), Environmental Justice. Key issues, ( Nueva York: Routledge, 2021). https://doi.org/10.4324/9780429029585

Diario Oficial de la Federación. "Decreto por el que se declara zona de monumentos arqueológicos el área conocida como Xochicalco, ubicada en los municipios de Temixco y Miacatlán, Mor.", 18 de febrero de 1994.

Diario de Morelos. "Venden Xochicalco a minera", 24 de marzo de 2015. http://www.diariodemorelos.com/content/venden-xochicalco-minera

Di Gregorio, M. "Networking in environmental movement organisations coalitions: interest, values or discourse?", Environmental politics, 1:21 (2012):1-25. https://doi.org/10.1080/09644016.2011.643366

Domínguez, N. C. "Niegan comuneros de Tetlama y Miacatlán negociaciones con minera", La Unión, 4 de marzo de 2015. https://www.launion.com.mx/morelos/zona-sur/noticias/68914-niegancomuneros-de-tetlama-y-miacatlán-negociaciones-con-minera.html Esperanza Silver Corporation. NI-43-101 Technical Report Cerro Jumil Project, Mexico, (Canadá: William D. Bond y Dean Turner/Esperanza Resources Corp, 2008). https://www.sec.gov/

Esperanza Silver de México S.A. de C.V. Manifestación de Impacto Ambiental Modalidad Particular, Mina Esperanza, Tetlama, Morelos, (México: Esperanza Silver de México/Planeación y Proyectos de Ingeniería S.C./Ordóñez Profesional S.C., 2013), [Folio 17MO2012M0005]

Esperanza Resources Corporation. NI-43-101 Updated Technical Report Preliminary Economic Assessment. Cerro Jumil Project, Morelos, México, (Colorado: Golder Associates Inc./Esperanza Resources Corp., 2011). http://www.alamosgold.com/home/default.aspx

Garibay, C. Clúster minero global: instauración de horizontes de coerción y resistencia en sociedades locales mexicanas, en Leticia Duran, Anja Nyjren, y Anne 
Cristina de Vega-Leitner, (eds.) Naturaleza y neoliberalismo en América Latina, ( UNAM, 2019),165-214. https://doi.org/10.22201/crim.9786073022231e.2019

Gobierno de Morelos. Decreto por el que se expide el Programa de Ordenamiento Ecológico Regional del Estado de Morelos, Periódico Oficial Tierra y Libertad, núm.

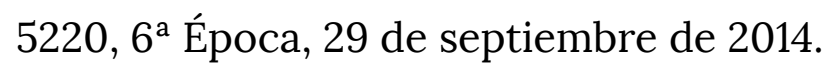

Gobierno de Morelos. "Lista planta de valorización en Xochitepec", 3 de junio de 2016. http://morelos.gob.mx/?q=prensa/nota/lista-planta-de-valorizacion-enxochitepec

Gobierno de Morelos. "Exhorta Graco Ramírez a cabildo de Temixco no aprobar la ejecución de la mina en Tetlama", 4 de junio de 2013 http://morelos.gob.mx/?q=exhorta-graco-ramírez-cabildo-de-temixco-noaprobar-la-ejecución-de-la-mina-en-tetlama

Gobierno de Morelos. Versión estenográfica del gobernador Graco Ramírez durante la inauguración de la Feria del Empleo de Turismo, 16 de octubre de 2012. https://morelos.gob.mx/

Gudynas, E. El nuevo extractivismo progresista del Sur. Tesis sobre un viejo problema bajo nuevas expresiones, en Acosta, et. al, Colonialismos del siglo XXI. Negocios extractivos y defensa del territorio en América Latina, (Barcelona: Icaria Editorial, 2011), 75-92.

Gudynas, E. Extracciones, extractivismo y extrahecciones. Un marco conceptual sobre la apropiación de los recursos naturales, Observatorio del Desarrollo, 8, ( Centro Latinoamericano de Ecología https://www.researchgate.net/publication/281748932_Extracciones_Extractivismo _y_Extrahecciones_Un_marco_conceptual_sobre_la_apropiacion_de_recursos_n aturales

Gutiérrez, L. "Alistan demanda penal contra minera Esperanza”, Diario de Morelos, 20 de marzo de 2013. https://www.diariodemorelos.com/article/alistan-demandapenal-contra-minera-esperanza.

Heynen, N.C and Swyngedouw, E. "Urban Political Ecology, Justice and the Politics of Scale", Antipode, 35:5, (2003), 898-918. https://doi.org/10.1111/j.14678330.2003.00364.x 
Hernández, F. "Cambian oro por centavos", Diario de Morelos, 24 de marzo de 2013. http://www.diariodemorelos.com/article/cambian-oro-por-centavos Hernández, F. "Se aferran comuneros a estar bien", Diario de Morelos, 24 de marzo de 2013. http://www.diariodemorelos.com/article/se-aferran-comuneros-'estar-bien'y-los-'espejitos'

Hernández, F. "Recibió minera apoyo federal", Diario de Morelos, 17 de junio de 2013. https://www.diariodemorelos.com/article/recibi\%C3\%B3-minera-apoyo-federal Hernández. F. "Se suman contra minera", Diario de Morelos, 8 de octubre de 2013. https://www.diariodemorelos.com/article/se-suman-contra-minera

Hernández, F. "Rechazan en Miacatlán labor minera", Diario de Morelos, 23 de marzo de 2014. http://www.diariodemorelos.com/article/rechazan-en-miacatlán-laborminera

Lander, E. "Tensiones/contradicciones en torno al extractivismo en los procesos de cambio: Bolivia, Ecuador y Venezuela", en Edgardo Lander, Carlos, Arze, Javier Gómez, Pablo Ospina y Víctor Álvarez, Promesas en su laberinto. Cambios y continuidades en los gobiernos progresistas en América Latina, (La Paz: Instituto de Estudios Peruanos/Centro de Estudios para el Desarrollo Laboral y Agrario/Centro Internacional Miranda, 2013), 1-35.

López Bárcenas, F. La vida o el mineral. Los cuatro ciclos del despojo minero en México, (Ciudad de México: Akal).

Merlinsky, G. (comp.). Cartografías del conflicto ambiental en Argentina, (Buenos Aires: Ciccus/CLACSO, 2013). http://biblioteca.clacso.edu.ar/clacso/se/20140228033437/Cartografias.pdf Merlinsky, G., Toledo, Virginia, Schmidt, Mariana, Fernández, Soledad, Tobías, Melina, Langbehn, Lorenzo, Pereira, Pablo. Y Capalbo, Tomas. Defender lo común. Qué podemos aprender de los conflictos ambientales, $1^{\text {ra }}$ edición, (Buenos Aires: Instituto de Investigaciones Gino Germani/Facultad de Ciencias Sociales-UBA/Grupo de Estudios Ambientales/Área de Estudios Urbanos, 2018). http://geaiigg.sociales.uba.ar/wp-content/uploads/sites/209/2019/07/LibroCuadernillo-Defender-lo-comun-VERSION-WEB.pdf 
Morales, R. "Continúan las presiones de la minera a cielo abierto Esperanza Silver en Tetlama", La Jornada Morelos, 24 de septiembre de 2014: http://www.jornadamorelos.com/2014/9/27/politica_nota_14.php

Murdock E. G., "A history of environmental justice. Foudations, narratives, and perspectives", en Brendan Coolsaet (ed.), Environmental Justice. Key issues, ( Nueva York: Routledge, 2021), 6-17. https://doi.org/10.4324/9780429029585

Paz, M.F. "Luchas en defensa del territorio. Reflexiones desde los conflictos socioambientales en México", Acta sociológica, 73, (Ciudad de México: UNAM, 2017), 197-219. DOI: http://dx.doi.org/10.1016/j.acso.2017.08.007

Paz, M.F. "Conflictos socioambientales en México: ¿qué está en disputa?”, en M.F. Paz y N. Risdell (coord.). Conflictos, conflictividades y movilizaciones socioambientales en México: problemas comunes, lecturas diversas, (Ciudad de México: UNAMCrim/MAPorrúa, 2014).

Paz, M.F. "Deterioro y resistencias. Conflictos socioambientales en México", en Darcy Tetreault, Heliodoro Ochoa y Eduardo Hernández (coords.), Conflictos socioambientales y alternativas de la sociedad civil, (Guadalajara: Instituto Tecnológico y de Estudios Superiores de Occidente, 2012), 27-47.

Pedroza, E. "Violentaron sus derechos, afirma minera", El regional del Sur, 11 de marzo de 2015.http://elregional.com.mx/Noticias/?id=64767

Peláez, P. "Legislación minera y derechos humanos: el derecho en la encrucijada", El cotidiano. Revista de la Realidad Mexicana Actual, 194, (Ciudad de México: UAMAzcapotzalco), 107-120. https://www.redalyc.org/articulo.oa?id=32542592011

Pellow, D.N., "Critical environmental justice studies", en Brendan Coolsaet (ed.), Environmental Justice. Key issues, (Nueva York: Routledge, 2021), https://doi.org/10.4324/9780429029585

Secretaría de Economía. Cartografía de concesiones mineras del Servicio Geológico Mexicano, 2017. https://www.sgm.gob.mx/GeoInfoMexGobMx/

Secretaría de Economía. Portafolio de proyectos mineros de la DGDM, 2015 https://www.gob.mx/se/acciones-y-programas/mineria-portafolio-de-proyectosde-la-dgdm 
Secretaría de Gobernación. Decreto por el que se crean los Consejos Consultivos para el Desarrollo Sustentable de la Secretaría de Medio Ambiente y Recursos Naturales, Diario Oficial de la Federación, Tomo DCXCVI, núm. 20, 29 de septiembre de 2011 http://www.dof.gob.mx/

Secretaría de Medio Ambiente y Recursos Naturales. Oficio No. SGPA/DGIRA/DG 03865, 5 de junio de 2013

Secretaría de Medio Ambiente y Recursos Naturales. Gaceta Ecológica, Año XI, Separata No DGIRA/007/2013, 14 de febrero de 2013.

7DíasTv. "Descubren mina de oro y plata en Tetlama", 2013 [video] https://www.youtube.com/watch?v=YrebxXLQJHo

Svampa, M. Del cambio de época al fin de ciclo. Gobiernos progresistas, extractivismo y movimientos sociales en América Latina, ( Buenos Aires: Edhasa, 2017).

Swyngedouw, E. "Scaled geographies: nature, place, and the politics of scale", en E. Sheppard y R. B. McMaster (ed.), Scale and geographic inquiry: nature, society and method, (Blackwell Publishing Ltd, 2004), 129-153. https://onlinelibrary.wiley.com/doi/book/10.1002/9780470999141

Swyngedouw, E., "Globalisation or 'glocalisation'? Networks, territories and rescaling", Cambridge Review of International Affairs, 17:1, (2004), 25-48. https://doi.org/10.1080/0955757042000203632

Sze, J. "Scale", en J. Adamson, J., William A. Gleason, David N. Pellow (eds.), Keywords for environmental studies, (New York: New York University Press, 2016), loc. 4743 of 6909, Kindle.

Sze, J., Jonathan London, Fraser Shilling, Gerardo Gambirazzio, Trina Filan y Mary Cadenasso, "Defining and contesting Environmental Justice: socio-natures and the politics of scale in the Delta", en Ryan Holifield, Michael Porter y Gordon Walker (eds.), Spaces of Environmental Justice, (Oxford: Antipode/ Wiley-Blackwell, 2010). https://doi.org/10.1002/9781444322767.ch8 


\title{
Environmental (In) Justice: Keys from Scale and Scalar Configuration
}

\begin{abstract}
In Mexico, the hegemonic status of the extractivism is being challenged by individuals, groups or communities affected by the consequences of large mining projects in Mexico. The socioenvironmental conflicts that emerge from extractivism express a complex network in which social actors, transnational corporations and state institutions converge and diverge. All of these actors form coalitions and act throughout the intervention of different geographical scales that in conflict, revealing ruptures or historical breaks that define and explain the social trajectory of conflict. Based on a case study, this paper presents a counterhegemonic episode in the extractivist development policy of the state, with the aim of discussing two key categories for political ecology and environmental justice: scale and scalar configuration. The socio-environmental conflict under study began in late 2012 due to the open-pit gold and silver mining project, known as "Cerro Jumil" or "Esperanza," located in centralwestern of Morelos State, Mexico.
\end{abstract}

Keywords: Socio-Environmental Conflicts; Extractivism; Scale; Scalar Configuration.

Recibido: 15/09/2021

Aprobado: 01/12/2021 